\section{Prevalence of hepatitis C and fibrosis stage per age group in Lebanese population}

\author{
Antoine Abou Rached, ${ }^{1}$ \\ Selim Abou Kheir, ${ }^{1}$ Jowana Saba, ${ }^{1}$ \\ Cezar Yaghi, ${ }^{2}$ Walid Ammar ${ }^{3}$ \\ ${ }^{1}$ Division of Gastroenterology, School of \\ Medicine, Lebanese University, Beirut; \\ ${ }^{2}$ Faculty of Medicine, Saint-Joseph \\ University, Hôtel Dieu de France \\ Hospital, Beirut; ${ }^{3}$ Ministry of Public \\ Health, Beirut, Lebanon
}

\begin{abstract}
In Lebanon, hepatitis $\mathrm{C}$ virus (HCV) prevalence is estimated to $0.2 \%$ among all ages, with genotype 1 the most common genotype. The age distribution shows 2 peaks reflecting 2 probable mode of transmission of HCV in Lebanon: 20-39 years and more than 40 years. The burden of HCV-related complications on the health system in Lebanon is expected to increase in the upcoming years. The number and prevalence per age group and the fibrosis stage of HCV infections is required to better estimate the burden of the disease in Lebanon. We calculated the prevalence per age group. Concerning fibrosis stage, patients recently diagnosed with $\mathrm{HCV}$ and never been treated previously were included and were divided into three groups according to their age Concerning the prevalence by age group, the lowest was seen in the group less than 20 years and the highest in the population aged more than 60 . Concerning the fibrosis by age group, the majority of patients less than 40 years had low fibrosis stage, while in the group of more than 60 years F3 and F4 represent respectively $15.07 \%$ and $68.49 \%$. Female gender had more significant fibrosis and cirrhosis than male gender. There is an exponential increase of significant fibrosis with age In Lebanon, the highest prevalence of hepatitis $\mathrm{C}$ is seen in the age group more than 60 years. In the 2 age groups (40-59 years and $>60$ years), we noted an advanced fibrosis stage and the majority of patient more than 60 years were cirrhotic at the time of diagnosis, which can reflect the burden of the disease in these groups.
\end{abstract}

\section{Introduction}

Chronic Hepatitis C virus (HCV) is the leading cause of chronic liver disease and is a serious health burden that requires urgent attention. About $55-85 \%$ of infected persons will develop chronic hepatitis C. ${ }^{1}$ Globally, 130-150 million people are chronically infected with $\mathrm{HCV}$, equivalent to 2.5 to $3.0 \%$ of the world's population. ${ }^{1,2}$

$\mathrm{HCV}$ is known as the silent epidemic. Patients are unaware of their disease until the development of complications. Cirrhosis (and subsequent hepatocellular carcinoma HCC) occurs in $15-35 \%$ of $\mathrm{HCV}$ patients after 25 to 30 years after infection, ${ }^{3}$ both becoming the leading cause of liver transplantation. Annually, HCV causes 700,000 deaths from different HCV-related liver diseases. ${ }^{1}$ Treatment of infected patients with hepatitis $\mathrm{C}$ can prevent the progression to $\mathrm{HCV}$ complications.

In Lebanon, HCV prevalence is estimated to $0.2 \%$ among all ages, with genotype 1 the most common genotype constituting $47 \%$ of cases followed by genotype $4.37 \%$. Based on the Ministry of Public Health (MOPH) estimation of the Lebanese population in 2012 around 4,093,307, we estimated that around 8618 patients are infected with hepatitis $\mathrm{C}$ virus in Lebanon. The age distribution shows 2 peaks reflecting 2 probable mode of transmission of $\mathrm{HCV}$ in Lebanon: 20-39 years (drug users), and more than 40 years (baby boomer and blood transfusion during the civil war in Lebanon).

The burden of HCV-related complications on the health system in Lebanon is expected to increase in the upcoming years due to the disease progression wave. A good understanding of the number and prevalence per age group and the fibrosis stage of $\mathrm{HCV}$ infections in Lebanon is required to better estimate the burden of the disease in Lebanon.

\section{Materials and Methods}

\section{Prevalence per age group}

We calculated the prevalence per age group based on the epidemiological study and the age distribution of patient infected with hepatitis $\mathrm{C}$ in Lebanon. Using the MOPH data concerning the estimated number of the Lebanese population, we calculated the prevalence of hepatitis $\mathrm{C}$ infection per age group (less than 20 years, 20 to 39 years, 40 to 59 years, and more than 60 years)

\section{Fibrosis stage}

Over a period of 24 months from November 2014 till November 2016 using the MOPH data, patients recently diagnosed with HCV and never been treated previously were included. Patients were divided into
Correspondence: Antoine Abou Rached, Division of Gastroenterology, Department of Internal Medicine, School of Medicine, Lebanese University, Hadath, Campus, PO Box \#3, Hadath, Beirut 2903 1308, Lebanon. E-mail: abourachedantoine@gmail.com

Key words: hepatitis C; prevalence; age; fibrosis stage.

Contributions: the authors contributed equally.

Conflict of interest: the authors declare no potential conflict of interest.

Received for publication: 11 April 2017.

Accepted for publication: 2 June 2017.

This work is licensed under a Creative Commons Attribution NonCommercial 4.0 License (CC BY-NC 4.0).

(C) Copyright A. Abou Rached et al., 2017

Licensee PAGEPress, Italy

Gastroenterology Insights 2017; 8:7180

doi:10.4081/gi.2017.7180

three groups according to their age: less than 40 years, between 40 and 59 years and more than 60 years. We determined the fibrosis stage, for each patient, based on the liver biopsy or the fibro scan results. Analysis was performed using the chisquare test to compare categorical data based on the SPSS (Statistical Package for the Social Sciences) software.

\section{Results}

\section{Prevalence by age group}

Taking into account the prevalence of $\mathrm{HCV}$ in Lebanon $(0.2 \%)$, the estimated percentage per age group and the total number of Lebanese population $(4,093,307)$, we calculated the prevalence in each age group (Table 1). The lowest prevalence was seen in the group less than 20 years and the highest in the population aged more than 60 .

\section{Fibrosis by age group}

During the period of 2 years (November 2014 till November 2016), the total number of newly diagnosed patients with $\mathrm{HCV}$ was 226 with $45 \%$ female and 55\% male. Concerning age distribution: 78 patients were less than 40 years, 75 patients between 40-59 years and 73 patients more than 60 years. The fibrosis stage was determined based on the liver biopsy or the fibro scan results for each patient chronically infected with hepatitis $\mathrm{C}$, then divided according to sex and age (less than 40 years, 40 to 59 
years, more than 60 years). Figure 1 represents the sex distribution of different fibrosis stage and Figure 2 the distribution of fibrosis per age group. The majority of patients less than 40 years had low fibrosis stage (F0: $65.4 \%$, F1: 23.1\%), in the group of 40 to 59 years F0, F1, F2, F3 and F4 were respectively $17.33 \%, 21.33 \%, 16 \%, 12 \%$, $33.33 \%$, while in the group of more than 60 years F3 and F4 represent respectively $15.07 \%$ and $68.49 \%$. Statistical analysis was done concerning the presence of significant fibrosis $(\geq F 2)$, results are shown in Tables 2 and 3. Female gender had more significant fibrosis than male gender $(61 \%$ vs $48 \%$ ) and more cirrhosis (41\% vs $29 \%$ ). There is an exponential increase of significant fibrosis with age $(11 \%, 62 \%$ and $92 \%$ in less than 40 years, 40 to 59 years and more than 60 years respectively) with significant difference in the same age group. Similar results were noted in patient with cirrhosis: $69 \%$ in age group more than 60 years versus $34 \%$ in 40 to 59 years versus $4 \%$ in less than 40 years and the difference was also statistically significant.

\section{Discussion}

In this cross-sectional study, we discussed first the prevalence of HCV in the different age group and then the fibrosis stage according to the age and gender in naive patients, over a period of two years, in Lebanon.

Based on age distribution, this study showed that the prevalence of HCV increases with age with the highest prevalence in Lebanon in the age group more than 60 years followed by the age group between 40 and 59 years reflecting the baby boomer population and those who received blood and blood product transfusions during civil war. The prevalence in this group exceeds that of the younger generation of less than 40 years which corresponds to IV drug users mostly.

In the United States, Australia, and countries in Western and Northern Europe, prevalence is highest among the baby boomer population, indicating high transmission over 20 to 40 years ago. Prevalence increases steadily with age in some countries, such as Spain, Italy, and Japan, patients greater than 50 years old account for most HCV infections. This suggests that the risk of acquiring $\mathrm{HCV}$ infection was higher over the last 40 to 60 years. In Egypt, where high rates of infection are observed in all age groups, indicating an ongoing high risk of acquiring infection. ${ }^{4}$

Many studies from different countries studied the prevalence of $\mathrm{HCV}$ in the different age groups.

In the US, of the estimated 3.2 million people with active $\mathrm{HCV}$ infection, most were born between 1945 and 1964 and were likely to be infected during the 1970 s and 1980s. ${ }^{5}$ Also, the prevalence of HCV in 1999 through 2002 was similar to that observed in 1988 through 1994, except that the peak prevalence shifted from patients between 30 and 39 to those between 40 and 49 years in the US. ${ }^{6,7}$

In France, in 2004, the prevalence of $\mathrm{HCV}$ has a peak in the age group 40-59 $(48.9 \%)$ then decrease slightly after the age of 60 . So, the highest HCV prevalence was in the age group more than $40 .{ }^{8}$ Cornberg showed a bimodal distribution of $\mathrm{HCV}$ prevalence in France at ages 40 to 49 years and 60 to 69 years, with the lowest prevalence in those aged between 18 to 29 years. ${ }^{9}$

Similarly, in Italy, it has been reported that around $60 \%$ of $\mathrm{HCV}$-infected subjects are currently older than 65 years. ${ }^{10}$

In Belgium, from1992 to 2002, the prevalence of $\mathrm{HCV}$ was $58 \%$ in patient under 50 years and $42 \%$ in the age group more than 50 . This reflects an increase in the prevalence of $\mathrm{HCV}$ with a rate of $3 \%$ in the last 6 years. ${ }^{11}$

In Spain, in 1996, HCV prevalence increases with age. The highest prevalence was found in the age group more than 64 . This is due most probably to previous blood transfusions and other parenteral methods

Table 1. Prevalence of hepatitis $\mathrm{C}$ virus in each age group.

\begin{tabular}{lcccc} 
Age & 0-19 years & 20-39 years & 40-59 years & $>60$ years \\
Estimated population & $1,409,664$ & $1,311,583$ & 842,666 & 529,394 \\
Age distribution, \% & 3 & 26 & 36 & 35 \\
\hline Number & 172 & 2327 & 3102 & 3016 \\
Prevalence, \% & 0.0122 & 0.1774 & 0.3725 & 0.5485 \\
\hline
\end{tabular}

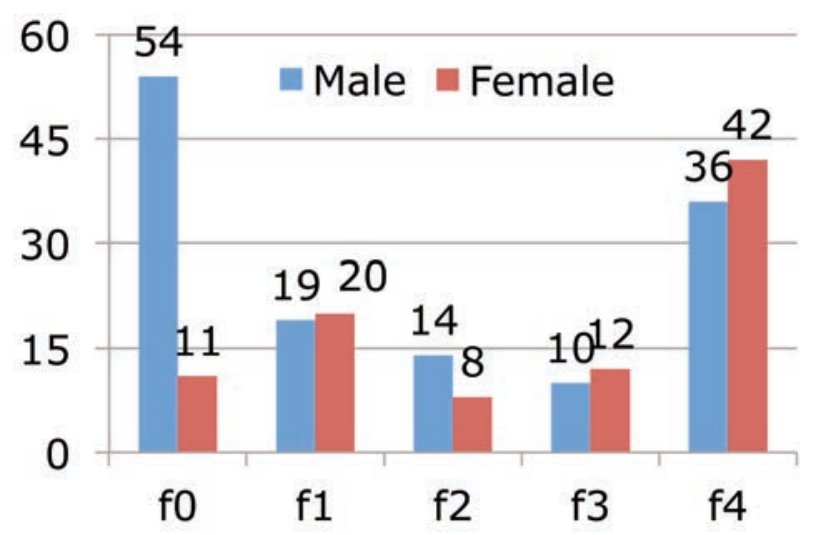

Figure 1. Sex distribution of different fibrosis stage.

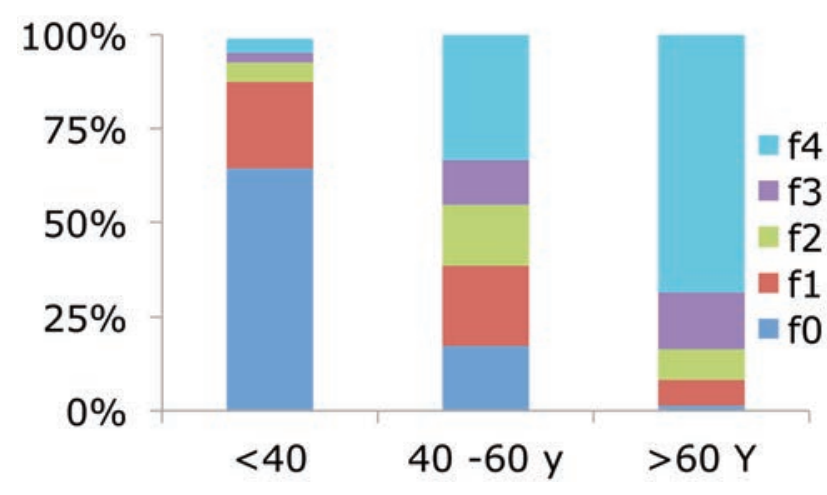

Figure 2. The distribution of fibrosis per age group. 
of transmission. ${ }^{12}$ This age distribution was the same in Turkey, Italy, Japan and China. ${ }^{13}$

In Japan, the prevalence of $\mathrm{HCV}$ increases with age and is shown to be much higher in people aged over 55 years. ${ }^{14}$

In Egypt, in 1997, the prevalence increases with age with a peak above the age of $40 .{ }^{15}$ This also was noticed in a comparative study of the prevalence of $\mathrm{HCV}$ in 2008 and 2015; but the age group more than 60 , which constitutes the reservoir of human HCV in Egypt, was excluded. ${ }^{16}$

Aging of the current HCV-infected patient population is associated with an increased risk of developing cirrhosis and HCC. ${ }^{17}$

Liver fibrosis is the result of the progressive accumulation and decreased remodeling of the extracellular matrix (ECM) leading to the disruption of the normal architecture of the liver. ${ }^{18}$ Fibrosis stage is involved in the prognosis.

There are strong evidences in favor of a nonlinear progression of fibrosis in hepatitis $\mathrm{C}$ patients with some individuals (often those aged $>50$ years) having a slow progression followed by an acceleration. Others may never develop substantial liver fibrosis despite longstanding infection.

Host factors found to be associated with a rapid fibrosis progression include longstanding infection, older age at the time of infection and male sex. ${ }^{19}$

Women clear acute HCV infection at a higher rate than do men, the clearance rate of blood HCV RNA appears to be higher in females. ${ }^{20}$

Demographic data from the United States, ${ }^{21}$ Europe (France ${ }^{22}$ and Italy ${ }^{23}$ ), and Japan $^{24}$ show that most HCV asymptomatic carriers are females, and have a good prognosis with a low risk of progression to cirrhosis and HCC.

While male gender is considered a risk factor, the results in our study were more favorable for an association between women and significant fibrosis (61\%). Cirrhosis cases were more prominent in female gender as well ( $41 \%$ vs $21 \%)$. If we follow the curve of fibrosis in women in our study we found an exponential increase with age from $\mathrm{SF}=7,7 \%(\mathrm{~F} 0-\mathrm{F} 1=92,3 \%)$ in the age group less than 40 to $\mathrm{SF}=86 \%$ (F0$\mathrm{F} 1=14 \%$ ) in the age group above 60 . Our reading compelling in the direction of a certain loss of the protective female gender effect in disease progression in elderly female patients with a chronic disease. Such a behavior was noted in elderly patients with chronic hepatitis $\mathrm{B}$ and results were attributed to interaction between the older age and female gender in chronic liver disease progression. ${ }^{25}$
The involvement of sex hormones could be an explanation for this phenomenon by affecting the HCV life cycle, immune response or the progression of associated liver disease as was mentioned in some studies concerning the chronic hepatitis B virus. $^{26}$

Other reports discussed that postmenopausal women with Chronic Hepatitis $\mathrm{C}$ or NAFLD had more severe hepatic steatosis and faster progression of liver fibrosis, ${ }^{27,28}$ while delayed menopause, taking oral contraceptives or postmenopausal hormone replacement therapy had a protective effect resulting in a slower progression. ${ }^{29,30}$

Estrogen may have a protective role against fibrosis in viral hepatitis by inhibiting stellate cells, which are responsible for fibrogenesis in the liver. ${ }^{31}$

And more specifically Estradiol inhibits reactive oxygen species generation, antioxidant enzyme loss, and hepatocyte death leading to decreased oxidative stressinduced transforming growth factor- $\beta$ (TGF- $\beta$ ) expression and hepatocyte stellate cell activation, enhancing antifibrotic activity. ${ }^{32}$

We can hypothesize that the loss of female gender protective effect against progression of liver fibrosis after the age of 50 years might be a result of decrease in estrogen level. This finding was reinforced in both Shimizu et al. study and southern/northern parts of China with an average age of 50 at menopause. ${ }^{33-35}$

Others factors, not discussed in our article were found by some authors to be associated with fibrosis progression like alcohol intake of more than $50 \mathrm{~g} / \mathrm{dL}$, and HIV coinfection. ${ }^{36}$ Also multiples studies reported the absence of association between genotype in hepatitis $\mathrm{C}$ and fibrosis progression, ${ }^{37,38}$ while others suggested the implication of genotype 3 as a risk factor for accelerated fibrosis progression. ${ }^{39}$ On the other hand there is no difference in fibrosis with respect to inter racial aspects. ${ }^{40}$

Many studies concluded that the most significant risk factors were existing fibrosis on the index biopsy and age at biopsy rather than the duration of infection suggesting a more fibrogenic tendency of hepatitis C with advancing host age. ${ }^{41}$ The underlying mechanisms for the relatively rapid progression of liver disease in older adults is not known. Possible mechanisms are higher susceptibility to environmental factors (especially oxidative stress), reduction in the rate of hepatic blood flow and reduced mitochondrial capacity. ${ }^{42}$ Higher prevalence of genotype 1, as well as impaired immunity, were proposed as well as an explanation for the significantly high- er viremic load in older patients. ${ }^{43,44}$

In a French study of patients with chronic hepatitis $\mathrm{C}$, the prevalence of severe fibrosis estimated by Fibro Test Acti Test was $73 \%$ among patients aged 65 years, compared with $35 \%$ among younger

Table 2. Statistical analysis of significant fibrosis $(\geq$ F2).

Significant fibrosis $\geq F 2$
Count, F0 Count, F1

Gender

$\begin{array}{lll}\text { Female } & 39 & 62 \\ \text { Male } & 65 & 60\end{array}$

\begin{tabular}{lcc} 
Age group & & \\
$<40$ years & 69 & 9 \\
$40-60$ years & 29 & 46 \\
$>60$ years & 6 & 67 \\
\hline
\end{tabular}

Age group by gender

$<40$ years, female $\quad 12$

$<40$ years, male

40-60 years, female

40-60 years, male

$>60$ years, female

$>60$ years, male

Gender by age group

Female, $<40$ years

Female, $40-60$ years

Female, $>60$ years

Male, $<40$ years

Male, $40-60$ years

Male, $>60$ years

$\begin{array}{cc}12 & 1 \\ 57 & 8 \\ 21 & 24 \\ 8 & 22 \\ 6 & 37 \\ 0 & 30\end{array}$

Table 3. Pearson chi-square tests.

\begin{tabular}{lc} 
& $\begin{array}{c}\text { Significant filbrosis } \\
(\geq \mathrm{F} 2)\end{array}$ \\
$\begin{array}{l}\text { Gender } \\
\text { chi-square }\end{array}$ & \\
df & 4.030 \\
sig. & 1 \\
Age group & $0.045^{*}$ \\
chi-square & \\
df & 100.182 \\
sig. & 2 \\
\hline
\end{tabular}

Age group

$<40$, gender, chi-square $\quad 0.226$

$<40$, gender, df

$<40$, gender, sig.

1

0.634

40-60, gender, df 1

40-60, gender, sig. $\quad 0.081$

$>60$, gender, chi-square $\quad 4.561$

$<60$, gender, df

$<60$, gender, sig.

1
$0.033^{* \circ}$

Gender

Female, age group, chi-square28.075

Female, age group, df 2

Female, age group, sig. $\quad 0.000^{*}$

Male, age group, chi-square 73.389

Male, age group, $\mathrm{df}$

Male, age group, sig.

2

Results are based on nonempty rows and columns in each innermost subtable. ${ }^{*}$ The Chi-square statistic is significant at the 0.05 level. ${ }^{\circ}$ More than $20 \%$ of cells in this subtable have expected cell counts less than 5 . Chi-square results may be invalid. 
patients. The authors concluded that fibrosis stage was higher for those aged more than 65 years regardless of infection duration. ${ }^{44}$

Other studies found that the progressive liver fibrosis and cirrhosis become more prevalent with age and occur in $2-20 \%$ of patients with long-term infection. ${ }^{37,45}$ Thein et al. found that the predicted cumulative probability of cirrhosis at 20 years after the infection was $16 \%$ (95\% CI, 14-19\%), and three-fold higher at 30 years $(41 \%, 36$ 45\%). ${ }^{39}$

This can be explained by the fact that first of all the duration of the infection is longer in older people and it is expected to have more severe disease. Second, older patients with mild disease are often asymptomatic, and they don't seek evaluation until advanced stages. ${ }^{46}$

Multiple studies reported a major acceleration in the rate of fibrosis after 50 years. ${ }^{41.47}$

Poynard et al. documented severe fibrosis/cirrhosis in $74.24 \%$ of patients above 40 years of age as compared to $33.3 \%$ of patients below 40 years. ${ }^{37}$ While Watson et al. demonstrated a strong correlation between fibrosis and age at biopsy, with patients over 50 years having a 131-fold increased risk of fibrosis stage 3 or 4 compared with patients aged less than 30 years (95\% CI 4.4-253). ${ }^{48}$

A study conducted on the US population, suggested that $27 \%$ of those born from 1945-1965 had advanced fibrosis or cirrhosis among the currently infected hepatitis C. Similarly, in this group of so called baby boomer the percentage with advanced fibrosis or cirrhosis was higher but constant $(27 \%, 26 \%, 28 \%$, and $28 \%)$ over a 4 -year period from 2010 to $2013(\mathrm{P}<0.0001) .{ }^{49}$ Another large US cohort of more than 10000 persons with HCV infection in home care, found that $38 \%$ had advanced fibrosis (F3) or cirrhosis (F4). ${ }^{50}$

The exponential increase of Fibrosis reaching a $\mathrm{SF}$ of $92 \%$ in the age group above 60 , more prominent in our study and less documented in others published before 2004, at least 10 years apart from the time of our study. This can explain this high prevalence of SF in the older age group.

\section{Conclusions}

The highest prevalence of hepatitis $\mathrm{C}$ is seen in the age group more than 60 years and is followed by the age group of 40 to 59 years. These 2 age groups most probably reflect the baby boomers known as the age wave of existing chronic $\mathrm{HCV}$ which are expected to contribute to a substantial rise in morbidity, mortality, and costs over the next 2 decades. In these 2 age groups, we noted an advanced fibrosis stage and the majority of patient more than 60 years were cirrhotic at the time of diagnosis, which can reflect the burden of the disease in these groups. HCV costs are expected to increase dramatically in the coming years because the most severe stages of the disease begin to manifest in the older population. An action should be done to prevent this and help minimize the socio-economic impact of non-treated patients.

\section{References}

1. WHO. Hepatitis C. Fact sheet. Available from: www.who.int/mediacentre/factsheets/fs 164/en

2. Goossens N, Hoshida Y. Hepatitis C virus-induced hepatocellular carcinoma. Clin Mol Hepatol 2015;21:105-14.

3. El-Serag HB. Epidemiology of viral hepatitis and hepatocellular carcinoma. Gastroenterology 2012;142:1264-73.

4. Alter MJ. Epidemiology of hepatitis C virus infection. World J Gastroenterol 2007; 13:2436-41

5. Centers for Disease Control and Prevention. Viral Hepatitis. People Born 1945-1965 (Baby Boomers). Available from: www.cdc.gov/hepatitis/populations/1945-1965.htm

6. Armstrong GL, Wasley A, Simard EP, et al. The prevalence of hepatitis $C$ virus infection in the United States, 1999 through 2002. Ann Intern Med 2006;144:705-14.

7. Alter MJ, Kruszon-Moran D, Omana $\mathrm{V}$, et al. The prevalence of hepatitis $\mathrm{C}$ virus infection in the United States, 1988 through 1994. N Engl J Med 1999;341:556-62.

8. Brouard C, Le Strat Y, Larsen C, et al. The undiagnosed chronically-infected $\mathrm{HCV}$ population in France. Implications for expanded testing recommendations in 2014. PLoS One 2015; 10:e0126920.

9. Cornberg M, Razavi HA, Alberti A, et al. A systematic review of hepatitis $C$ virus epidemiology in Europe, Canada and Israel. Liver Int 2011;31:30-60.

10. Mariano A, Scalia Tomba G, Tosti ME, et al. Estimating the incidence, prevalence and clinical burden of hepatitis $\mathrm{C}$ over time in Italy. Scand J Infect Dis 2009;41:689-99.

11 Gérard C, Delwaide J, Vaira D, et al. Evolution over a 10 year period of the epidemiological profile of 1,726 newly diagnosed $\mathrm{HCV}$ patients in Belgium. J Med Virol 2005;76:503-10.

12. Domínguez À, Bruguera M, Vidal J, et al. Community-based seroepidemiological survey of $\mathrm{HCV}$ infection in Catalonia, Spain. J Med Virol 2001;65:688-93.

13. Alter MJ. Epidemiology of hepatitis C virus infection. World J Gastroenterol 2007; 13:2436-41.

14. Chung H, Ueda T, Kudo M. Changing trends in hepatitis $\mathrm{C}$ infection over the past 50 years in Japan. Intervirology 2010;53:39-43.

15. Abdel-Aziz F, Habib M, Mohamed MK, et al. Hepatitis $\mathrm{C}$ virus (HCV) infection in a community in the Nile delta: population description and $\mathrm{HCV}$ prevalence. Hepatology 2000;32:111-5.

16. Kandeel A, Genedy M, El $\square$ Refai S, et al. The prevalence of hepatitis $C$ virus infection in Egypt 2015: implications for future policy on prevention and treatment. Liver Int 2017;37:45-53.

17. Davila JA, Morgan RO, Shaib Y, et al. Hepatitis $\mathrm{C}$ infection and the increasing incidence of hepatocellular carcinoma: a population-based study. Gastroenterology 2004;127:1372-80.

18. Iredale JP. Models of liver fibrosis: exploring the dynamic nature of inflammation and repair in a solid organ. $J$ Clin Invest 2007;117:539-48.

19. Ghany MG. Progression of fibrosis in chronic hepatitis C. Gastroenterology 2003;124:97-104.

20. Bakr I, Rekacewicz C, Hosseiny ME, et al. Higher clearance of hepatitis $C$ virus infection in females compared with males. Gut 2006;55:1183-7.

21. Gholson CF Morgan K, Catinis G, et al. Chronic hepatitis $\mathrm{C}$ with normal aminotransferase levels: a clinical histologic study. Am J Gastroenterol 1997;92:1788-92.

22. Renou C, Halfon $\mathrm{P}$, Pol S, et al. Histological features and HLA class II alleles in hepatitis $\mathrm{C}$ virus chronically infected patients with persistently normal alanine aminotransferase levels. Gut 2002;51:585-90.

23. Puoti C, Castellacci R, Montagnese F, et al. Histological and virological features and follow-up of hepatitis $\mathrm{C}$ virus carriers with normal aminotransferase levels: the Italian prospective study of the asymptomatic C carriers (ISACC). J Hepatol 2002;37:117-23.

24. Okanoue T, Makiyama A, Nakayama $\mathrm{M}$, et al. A follow-up study to determine the value of liver biopsy and need for antiviral therapy for hepatitis $\mathrm{C}$ virus carriers with persistently normal serum aminotransferases. J Hepatol 2005;43:599-605.

25. You H, Kong Y, Hou J, et al. Female gender lost protective effect against dis- 
ease progression in elderly patients with chronic hepatitis B. Sci Rep 2016;6:37498.

26. Wang SH, Chen PJ, Yeh SH. Gender disparity in chronic hepatitis B: mechanisms of sex hormones. J Gastroenterol Hepatol 2015;30:1237-45.

27. Codes L, Asselah T, Cazals-Hatem D, et al. Liver fibrosis in women with chronic hepatitis c: evidence for the negative role of the menopause and steatosis and the potential benefit of hormone replacement therapy. Gut 2007;56:3905.

28. Yang JD, Abdelmalek MF, Pang H, et al. Gender and menopause impact severity of fibrosis among patients with nonalcoholic steatohepatitis. Hepatology (Baltimore) 2014;59:140614.

29. Yu MW, Chang HC, Chang SC, et al. Role of reproductive factors in hepatocellular carcinoma: Impact on hepatitis B- and C-related risk. Hepatology 2003;38:1393-400.

30. Xi B, He D, Hu Y, Zhou D. Prevalence of metabolic syndrome and its influencing factors among the Chinese adults: the China health and nutrition survey in 2009. Prev Med 2013;57:867-71.

31. Bissell DM. Sex and hepatic fibrosis. Hepatology 1999;29:988-9.

32. Shimizu I, ed. Preventive female sex factors against the development of chronic liver disease. Dubai: Bentham Science Publishers.

33. Shimizu I. Impact of oestrogens on the progression of liver disease. Liver Int
2003;23:63-9.

34. Li L, Wu J, Pu D, et al. Factors associated with the age of natural menopause and menopausal symptoms in Chinese women. Maturitas 2012;73:354-60.

35. Liu K, He L, Tang X, et al. Relationship between menopause and health-related quality of life in middle-aged Chinese women: a cross-sectional study. BMC Womens Health 2014;14:7.

36. Freeman A J, Dore GJ, Law MG, et al. Estimating progression to cirrhosis in chronic hepatitis $\mathrm{C}$ virus infection. Hepatology 2001;34:809-16.

37. Poynard T, Ratziu V, Charlotte F, et al. Rates and risk factors of liver fibrosis progression in persons with chronic hepatitis C. J Hepatol 2001;34:730-9.

38. Reggiardo MV. Natural history of hepatitis $\mathrm{C}$ virus infection in a cohort of asymptomatic post-transfused subjects. Ann Hepatol 2012;11:658-66.

39. Thein HH, Yi Q, Dore GJ, Krahn MD. Estimation of stage-specific fibrosis progression rates in chronic hepatitis $\mathrm{C}$ virus infection: A meta-analysis and meta-regression. Hepatology 2008;48:418-31.

40. Siddiqui FA, Ehrinpreis MN, Janisse J, et al. Demographics of a large cohort of urban chronic hepatitis $\mathrm{C}$ patients. Hepatol Int 2008;2:376-81.

41. Ryder SD. Progression of hepatic fibrosis in patients with hepatitis $\mathrm{C}$ : a prospective repeat liver biopsy study. Gut 2004;53:451-5.

42. Horiike N, Masumoto T, Nakanishi K, et al. Interferon therapy for patients more than 60 years of age with chronic hepatitis C. J Gastroenterol Hepatol 1995;10:246-9.

43. Kao JH, Lai MY, Chen PJ, et al. Clinical significance of serum hepatitis $\mathrm{C}$ virus titers in patients with chronic type $\mathrm{C}$ hepatitis. Am J Gastroenterol 1996;91:506-10.

44. Thabut D, Calvez SL, Thibault V, et al. Hepatitis C in 2410 patients 65 years or older: a severe and neglected curable disease? Hepatology 2003;38:424A.

45. Seeff LB. Natural history of chronic hepatitis C. Hepatology 2002;36:s3546.

46. McHutchison JG. Understanding hepatitis C. Am J Manag Care 2004; 10:S219.

47. Mohsen AH, Group THS. The epidemiology of hepatitis $C$ in a UK health regional population of 5.12 million. Gut 2001;48:707-13.

48. Watson JP, Brind AM, Chapman CE, et al. Hepatitis $\mathrm{C}$ virus: epidemiology and genotypes in the north east of England. Gut 1996;38:269-76.

49. Monina K, Lauren C, Xiaohua H, et al The burden of hepatitis $\mathrm{C}$ infectionrelated liver fibrosis in the United States. Clin Infect Dis 2016;63:104955.

50. Holmberg SD, Lu M, Rupp LB, Lamerato LE, et al. Noninvasive serum fibrosis markers for screening and staging chronic hepatitis $\mathrm{C}$ virus patients in a large US cohort. Clin Infect Dis 2013;57:240-6. 